\title{
Metformin Impairs Endothelialization After Placement of Newer Generation Drug Eluting Stents
}

\author{
Anwer Habib, MD, Vinit Karmali, MA, Rohini Polavarapu, BA, Hirokuni Akahori, MD, PhD, \\ Kim Pachura, BS, and Aloke V. Finn, MD \\ Department of Internal Medicine, Emory University School of Medicine, Atlanta, Georgia
}

\begin{abstract}
Objectives-Metformin impairs endothelialization of drug eluting stents (DES) due to convergent signaling at the mammalian target of rapamycin (mTOR) pathway. We assessed whether metformin will continue to adversely affect stent endothelialization despite design improvements in newer generation DES.
\end{abstract}

Methods-Rabbit iliac artery stenting with newer generation DES was performed followed by 14 days of either normal chow diet or one with metformin $(100 \mathrm{mg} / \mathrm{kg} /$ day $)$ added. Scanning electron microscopy was used to assess stent endothelialization after sacrifice.

Results-In the metformin-treated group there was significantly less endothelialization compared to the placebo-treated group. Paclitaxel-eluting stents in placebo-treated group had the greatest degree of endothelialization with significantly less in its metformin-treated counterpart and all -limus eluting stent groups.

Conclusions-Metformin inhibited stent endothelialization in newer generation DES despite improvements in stent design. By impairing stent endothelialization, metformin may increase the risk for thrombotic complications after newer generation DES placement.

\section{Keywords}

Metformin; Vascular Endothelium; Drug Eluting Stents

\section{Introduction}

Patients with diabetes are at increased risk for the development of coronary artery disease. Treatment of symptomatic coronary artery disease with drug eluting stents (DES) in the diabetic population represents a significant advance by preventing stent restenosis which is a major limitation of this procedure $(1,2)$. However, in diabetic patients, the long term safety profile of DES is limited by an increased risk of late stent thrombosis, which is thought to be

() 2013 Elsevier Ireland Ltd. All rights reserved.

Corresponding Author: Aloke Virmani Finn, MD, Emory University, 101 Woodruff Circle, WMB 319B, Atlanta, Georgia 30322, Phone: 404686 2508, Fax: 404686 5764, avfinn@emory.edu.

Publisher's Disclaimer: This is a PDF file of an unedited manuscript that has been accepted for publication. As a service to our customers we are providing this early version of the manuscript. The manuscript will undergo copyediting, typesetting, and review of the resulting proof before it is published in its final citable form. Please note that during the production process errors may be discovered which could affect the content, and all legal disclaimers that apply to the journal pertain.

Disclosures

AVF has sponsored research agreements with Medtronic CardioVascular and Boston Scientific. He is also an advisory board member to Medtronic CardioVascular. AH is supported with an American Heart Association post-doctoral fellowship grant (Greater Southeast Affiliate). All other authors have reported that they have no relationships relevant to the contents of this paper to disclose. 
due to poor stent endothelialization $(1,3)$. While an explanation for this increased risk is unknown, recent studies have suggested mammalian target of rapamycin (mTOR) inhibitors, which are eluted from most DES, share convergent molecular signaling with commonly used diabetic medication such as metformin which results in impaired endothelialization (4). However, it remains unknown whether this same interaction applies to newer generation DES which are characterized by improvements in stent design and polymer biocompatibility while utilizing either newer mTOR inhibitors based agents or paclitaxel (5). The objective of this study was to compare stent endothelialization in newer generation DES with and without metformin treatment in a pre-clinical animal model of arterial stenting.

\section{Methods}

Twenty-six New Zealand White Male rabbits from 3.0 to $3.5 \mathrm{~kg}$ underwent iliac artery injury and stenting with either paclitaxel-eluting stents (PES, Ion Paclitaxel Eluting Coronary Stent, Boston Scientific, $3.0 \times 12 \mathrm{~mm}$, Boston, MA, USA), everolimus-eluting stents (EES, Promus-Element, $3.0 \times 12 \mathrm{~mm}$, Boston Scientific) or zotarolimus-eluting stents (ZES, Resolute-Integrity, $3.0 \times 12 \mathrm{~mm}$, Medtronic, Minneapolis, MN, USA) deployed at a target stent-to-artery ratio of 1.3:1 as previously described (4). All animals were anticoagulated with aspirin ( $40 \mathrm{mg} /$ day) given orally 24 -hours before catheterization with continued dosing throughout the study while single dose intra-arterial heparin (150 IU/kg) was administered at the time of catheterization. Rabbits were randomized equally and fed standard chow diet or one with Metformin ( $100 \mathrm{mg} / \mathrm{kg} / \mathrm{day}$ per os) added for fourteen days after stenting (6). Metformin dosing was based on equivalent dosing of $2 \mathrm{gm} / \mathrm{day}$ in humans (4). Point of care testing for blood glucose (Roche, Basel, Switzerland) was performed with no incidence of hypoglycemia in either group before or after stent placement. Animals were sacrificed at the end of the study, perfused with normal saline followed fixing with $4 \%$ paraformaldehyde and processed for scanning electron microscopy. The study protocol was in compliance with the Guide for the Care and Use of Laboratory Animals published by the US National Institutes of Health and approved by the Emory University Institutional Animal Care and Use Committee. Stents were analyzed by scanning electron microscopy and percent endothelialization was calculated as previously described (4). Statistical analysis was performed JMP Pro v10 (SAS, Cary, NC). All data was expressed as mean \pm SD. Differences were evaluated using two-way analysis of variance (ANOVA) for multiple comparisons followed by Tukey HSD post-hoc test when the F-test was significant. A pvalue of $<0.05$ was considered statistically significant.

\section{Results}

There was significant inhibition of stent endothelialization in Metformin-fed animals compared with standard chow diet among all stent types $(\mathrm{p}=0.01)$ (figure 1 and table 1$)$. The PES-standard chow diet had the greatest stent endothelialization at 14 days which compared with all -limus based groups ( $\mathrm{p}<0.0001)$ and the PES-Metformin group $(\mathrm{p}=$ 0.038 ) (table 1). When comparing stent types, animals receiving -limus based stents had less endothelialization when compared with PES $(\mathrm{p}<0.0001)$ and stent endothelialization was the least with EES and ZES groups treated with Metformin. There was no significant interaction term between stent type and treatment group $(\mathrm{p}=0.544)$.

\section{Discussion}

Metformin is the most commonly prescribed anti-diabetic medication with increasing evidence suggesting that it also has anti-proliferative properties through its action on the mammalian target of rapamycin (mTOR) pathway $(4,7)$. This study suggests that metformin in combination with newer generation -limus and paclitaxel DES acts to impair stent 
endothelialization despite improvements in stent design. We have previously shown that metformin and mTOR inhibitors, such as sirolimus, converge on S6 kinase, a downstream target of the mTOR complex 1, leading to suppression of key regulators of the S/G1 cycle progression such as cyclin D1 $(4,8)$. Paclitaxel, a taxane, impairs microtubule formation suppressing the mitotic phase and creating a cytotoxic environment by promoting increased apoptosis (8). Metformin in combination with paclitaxel likely suppresses endothelialization through its combined effect on apoptosis $(4,8)$. Overall these findings, as well as recent clinical trials, suggest that non-insulin dependent diabetic patients treated with both metformin and current generation DES may potentially be at increased risk of impaired stent endothelialization, stent thrombosis and poorer outcomes $(9,10)$. Our study is limited by the use of a non-diabetic animal model and likely leads to an overall underestimation of the degree of endothelial inhibition as diabetes may further impair endothelialization in the setting of injury (4). Given this increased risk, prolonged dual anti-platelet therapy beyond the indicated period may be beneficial in diabetic patients on chronic metformin therapy (11).

\section{Acknowledgments}

\section{Funding Sources}

This study was supported by the Carlyle Fraser Heart Center, Boston Scientific, American Heart Association and US NIH grant RO1 HL096970-01A. The funding sources did not play a role in the construction of the study, writing of the manuscript or decision for publication.

\section{References}

1. Palmerini T, Biondi-Zoccai G, Della Riva D, et al. Stent thrombosis with drug-eluting and baremetal stents: evidence from a comprehensive network meta-analysis. Lancet. 2012; 379:1393-1402. [PubMed: 22445239]

2. Bangalore S, Kumar S, Fusaro M, et al. Outcomes with various drug eluting or bare metal stents in patients with diabetes mellitus: mixed treatment comparison analysis of 22,844 patient years of follow-up from randomised trials. Bmj. 2012; 345:e5170. [PubMed: 22885395]

3. Finn AV, Joner M, Nakazawa G, et al. Pathological correlates of late drug-eluting stent thrombosis: strut coverage as a marker of endothelialization. Circulation. 2007; 115:2435-2441. [PubMed: 17438147]

4. Habib A, Karmali V, Polavarapu R, et al. Metformin impairs vascular endothelial recovery after stent placement in the setting of locally eluted Mammalian target of rapamycin inhibitors via s6 kinase-dependent inhibition of cell proliferation. Journal of the American College of Cardiology. 2013; 61:971-980. [PubMed: 23449430]

5. Stefanini GG, Holmes DR Jr. Drug-eluting coronary-artery stents. The New England journal of medicine. 2013; 368:254-265. [PubMed: 23323902]

6. Joner M, Nakazawa G, Finn AV, et al. Endothelial cell recovery between comparator polymer-based drug-eluting stents. Journal of the American College of Cardiology. 2008; 52:333-342. [PubMed: 18652940]

7. Dowling RJ, Goodwin PJ, Stambolic V. Understanding the benefit of metformin use in cancer treatment. BMC Med. 2011; 9:33. [PubMed: 21470407]

8. Wessely R, Schomig A, Kastrati A. Sirolimus and Paclitaxel on polymer-based drug-eluting stents: similar but different. Journal of the American College of Cardiology. 2006; 47:708-714. [PubMed: 16487832]

9. Gwon HC, Hahn JY, Park KW, et al. Six-month versus 12-month dual antiplatelet therapy after implantation of drug-eluting stents: the Efficacy of Xience/Promus Versus Cypher to Reduce Late Loss After Stenting (EXCELLENT) randomized, multicenter study. Circulation. 2012; 125:505513. [PubMed: 22179532] 
10. Stone GW, Kedhi E, Kereiakes DJ, et al. Differential clinical responses to everolimus-eluting and Paclitaxel-eluting coronary stents in patients with and without diabetes mellitus. Circulation. 2011; 124:893-900. [PubMed: 21824922]

11. Levine GN, Bates ER, Blankenship JC, et al. 2011 ACCF/AHA/SCAI Guideline for Percutaneous Coronary Intervention: a report of the American College of Cardiology Foundation/American

Heart Association Task Force on Practice Guidelines and the Society for Cardiovascular Angiography and Interventions. Circulation. 2011; 124:e574-e651. [PubMed: 22064601] 


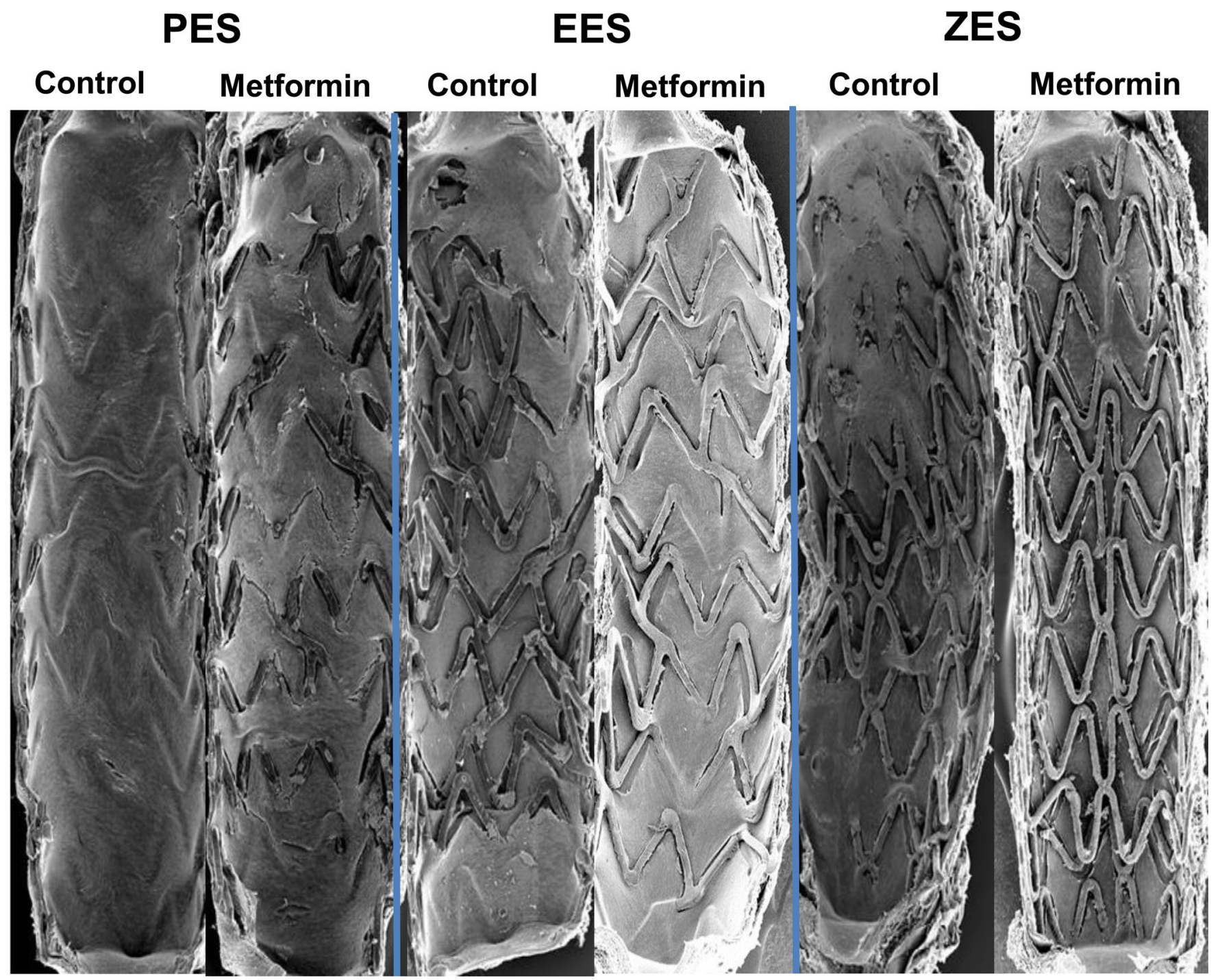

Figure 1. Endothelial Stent Strut Endothelialization is Impaired in Newer Generation Drug Eluting Stents (DES) in Combination with Oral Metformin in the Rabbit Iliac Model of Arterial Stenting

Representative scanning electron micrographs (15x) of 14-day paclitaxel eluting stents (PES), everolimus- and zotarolimus-eluting stents (EES, ZES) in the presence or absence of oral Metformin $(100 \mathrm{mg} / \mathrm{kg} / \mathrm{day})$ treatment. 
Table 1

Evaluation of \% Endothelialization at 14-day by Scanning Electron Microscopy

\begin{tabular}{|c|c|c|c|}
\hline & $\begin{array}{c}\text { Ion**, }{ }^{*} \\
(\mathbf{n}=\mathbf{8})\end{array}$ & $\begin{array}{c}\text { Promus Element } \\
(\mathbf{n}=\mathbf{8})\end{array}$ & $\begin{array}{c}\text { Endeavor Resolute } \\
(\mathbf{n = 1 0})\end{array}$ \\
\hline $\begin{array}{c}\text { Control } \\
(\mathrm{n}=13 \text { animals })\end{array}$ & $67.7 \pm 30.5$ & $24.3 \pm 16.1$ & $16.3 \pm 16.2$ \\
\hline $\begin{array}{c}\text { Metformin } \\
(\mathrm{n}=13)\end{array}$ & $48.2 \pm 23.5$ & $10.4 \pm 10.2$ & $10.0 \pm 13.4$ \\
\hline
\end{tabular}

Data expressed as mean \pm standard deviation.

* Metformin is significantly different from Control $(\mathrm{p}=0.01)$.

*** Ion is significantly different from Promus Element and Endeavor Resolute stent $(\mathrm{p}<0.0001)$.

${ }^{\dagger}$ Ion-Control is significantly different than Ion-Metformin $(\mathrm{p}=0.038)$. 